\title{
Cytomorphometric changes in hippocampal CA1 neurons exposed to simulated microgravity using rats as model
}

\author{
Amit Ranjan ${ }^{1,2}$, Jitendra Behari ${ }^{2}$ and Birendra N. Mallick ${ }^{1}$ * \\ ' School of Life Sciences, Jawaharlal Nehru University, New Delhi, India \\ 2 School of Environmental Sciences, Jawaharlal Nehru University, New Delhi, India
}

\section{Edited by:}

George P. Chrousos, Athens

University Medical School, Greece

Reviewed by:

Axel Hutt, INRIA CR Nancy, France George P. Chrousos, Athens

University Medical School, Greece

*Correspondence:

Birendra N. Mallick, School of Life

Sciences, Jawaharlal Nehru

University, New Delhi 110067, India

e-mail:remsbnm@yahoo.com
Microgravity and sleep loss lead to cognitive and learning deficits. These behavioral alterations are likely to be associated with cytomorphological changes and loss of neurons. To understand the phenomenon, we exposed rats $(225-275 \mathrm{~g})$ to 14 days simulated microgravity (SMg) and compared its effects on CA1 hippocampal neuronal plasticity, with that of normal cage control rats. We observed that the mean area, perimeter, synaptic cleft, and length of active zone of CA1 hippocampal neurons significantly decreased while dendritic arborization and number of spines significantly increased in SMg group as compared with controls. The mean thickness of the postsynaptic density and total dendritic length remained unaltered. The changes may be a compensatory effect induced by exposure to microgravity; however, the effects may be transient or permanent, which need further study. These findings may be useful for designing effective prevention for those, including the astronauts, exposed to microgravity. Further, subject to confirmation, we propose that SMg exposure might be useful for recovery of stroke patients.

Keywords: dendritic arborization, Golgi-Cox, learning and memory, length of active zone, neuronal plasticity, spine density

\section{INTRODUCTION}

Human astronauts who spent more than 400 days in space showed ataxia, perceptual illusions, neuromuscular weakness, and fatigue after landing. They tended to readapt with time under normal gravity condition after returning to the earth (1). During space travel, astronauts are exposed to many factors including microgravity and hypergravity. Exposure to microgravity induces changes in the brain, which possibly are underlying causes that are reflected as many of the altered physio-behavioral changes seen in the astronauts. Independent studies have reported that exposure to microgravity alters levels of biomolecules (2-4), increase cortical spine density (5), induce impaired cognition as well as learning and memory $(6,7)$. These impairments are likely to be specific to exposure to microgravity because such microgravity exposure-associated loss of memory $(8,9)$ tended to reverse with time after their return to the earth under normal gravity condition (10). Notwithstanding, other studies have reported that 6 (11) and $8(12,13)$ days spaceflight showed no impairment of memory, however, 13 (14) and 16 (10) days exposure showed some impairment. Therefore, microgravity exposure-associated impairments of cognitive functions are likely to be dependent on duration of exposure and the effects varied depending on the rate of recovery and degree of adaptation. On the other hand, isolated studies have shown that impaired learning and memory is associated with reduced spine density (15) and neuronal loss $(16,17)$.

Apparently there is an inherent contradiction that exposure to microgravity caused impairment of memory associated with increased spine density, while otherwise memory impairment is associated with neuronal loss and reduced spine density, which indeed needed investigation under suitable controlled experimental (simulated) conditions. One possibility could be that the changes in spine density due to exposure to microgravity could be a compensatory effect and there could be other microcytomorphological changes as an indication of initial signs of possible loss of neurons $(18,19)$, which were unknown. Further, as hippocampal neurons are involved in memory formation (20) and the latter is altered by exposure to microgravity $(6,8)$, we argued that exposure to simulated microgravity $(\mathrm{SMg})$ under controlled experimental condition is likely to affect the hippocampal CA1 neurons. Therefore, in this study, we exposed rats to 14 days $\mathrm{SMg}$ and evaluated CA1 neuronal cytomorphometry, arborization, dendritic spine density, synaptic cleft (SC), length of active zone (LAZ), and thickness of postsynaptic density (PSD). It was observed that neuronal morphology and synaptic connectivity were damaged suggesting initial changes of neuronal loss; however, the silver lining is that there is a possibility of compensation and recovery.

\section{MATERIALS AND METHODS ANIMAL PREPARATION}

Experiments were conducted on inbred male Wistar rats (225$275 \mathrm{~g}$ ) maintained in 12/12 h light/dark cycle with food and water ad libitum. NIH guidelines were followed while conducting experiments and all experiments were approved by the Institutional Animal Ethics Committee of Jawaharlal Nehru University. Every step was taken to reduce number of animals used and their sufferings. Rats were subjected to SMg using hind-limb suspended (HLS) model, which has been widely used for such studies (2123), while control rats were maintained in their normal cages in the same room to rule out non-specific effects. For SMg exposure, the 
rats were lifted with a tail harness that raised their hind-limbs $1 \mathrm{~cm}$ off the cage floor in a $30^{\circ}$ head-down angle and maintained for 14 days. We have considered only those experimental rats for cytomorphometric analysis in which the body weight of experimental rats followed the pattern as reported earlier (22). Commenting on the weight of normal adult rats $(>200 \mathrm{~g})$, upon exposure to SMg it has been stated that "rats may lose or gain weight more slowly for several days after initial unloading, followed by stabilization of body weight" (22). In this study, we observed that weight loss or gain was not consistent up to the seventh day of exposure. However, thereafter the rats gained weight, which was stabilized by the 14th day of exposure and hence 14-day exposure paradigm was used in this study. The animals were randomly divided into three groups (Figure 1).

\section{NISSL-STAINING METHOD}

At the end of experiment, eight rats (four control and four experimental) were anesthetized with ketamine-xylazine (80 and $32 \mathrm{mg} / \mathrm{kg}$, respectively, i.p.; Chandra Bhagat Pharma Pvt. Ltd., India). The brains were intracardially perfused with $0.1 \mathrm{M}$ phosphate buffer saline (PBS) and 4\% paraformaldehyde in $0.1 \mathrm{M}$ phosphate buffer (PB) at $\mathrm{pH}$ 7.4. Brains were fixed overnight in the same fixative and were cryoprotected in $30 \%$ sucrose in PBS. Thereafter, $40 \mu \mathrm{m}$ frozen sections (Leica, Solms, Germany) through the antero-posterior extension of hippocampus [between bregma -2.30 and $-5.30 \mathrm{~mm}$ as in atlas of Paxinos and Watson (24)] were taken onto gelatin-coated slides, processed for Nisslstaining, and analyzed as reported earlier in detail $(25,26)$. Briefly, the sections were stained with $1 \%$ cresyl violet and $0.1 \%$ thionin in acetate buffer following standard protocol of Nissl-staining. The stained sections were dehydrated in different grades of ethanol, cleared in xylene, cover slipped with distrene plasticizer xylene (DPX), and air dried before viewing under microscope for cytomorphometric analysis. The slides were coded before the CA1 hippocampal neurons were analyzed. The boundaries of 30-40 neuronal perikarya from every third serial section were traced on the computer screen (with the help of a computer mouse) and their areas as well as perimeters estimated by using cytomorphometric analysis software (Image-Pro plus 5.1.1). Six to eight such sections from each animal were estimated and there were four animals per treatment group. Thus, on an average $850 \pm 50$ neurons were estimated from anatomical CA1 brain areas of experimental as well as control rats. The mean area and perimeter data were used to calculate the soma form factor (FF) $\left(4 \pi\right.$ area/perimeter $\left.{ }^{2}\right)$, which is a parameter to comment on shape of the cell. The cells having FF values closure to 1 would be relatively rounder in shape than those closure to 0 (27). Further, rough surfaced cells would have greater possibility to change FF than smoother surfaced cells $(25,26)$.

\section{GOLGI-COX IMPREGNATION METHOD}

In Nissl-staining, the neurons were seen in one plane (2-D). However, as neurons occupy volume in space, to get information in 3-D, we used Golgi-Cox impregnation method and reasonably extrapolated possible changes in CA1 neurons after exposure to 14 days $\mathrm{SMg}$. Brains of another set of six each of control and experimental rats were treated with Golgi stain as reported earlier (28). Anesthetized rats were perfused transcardially with $0.1 \mathrm{M}$ PBS solution at $\mathrm{pH}$ 7.4. All the brains were removed, washed with distilled water

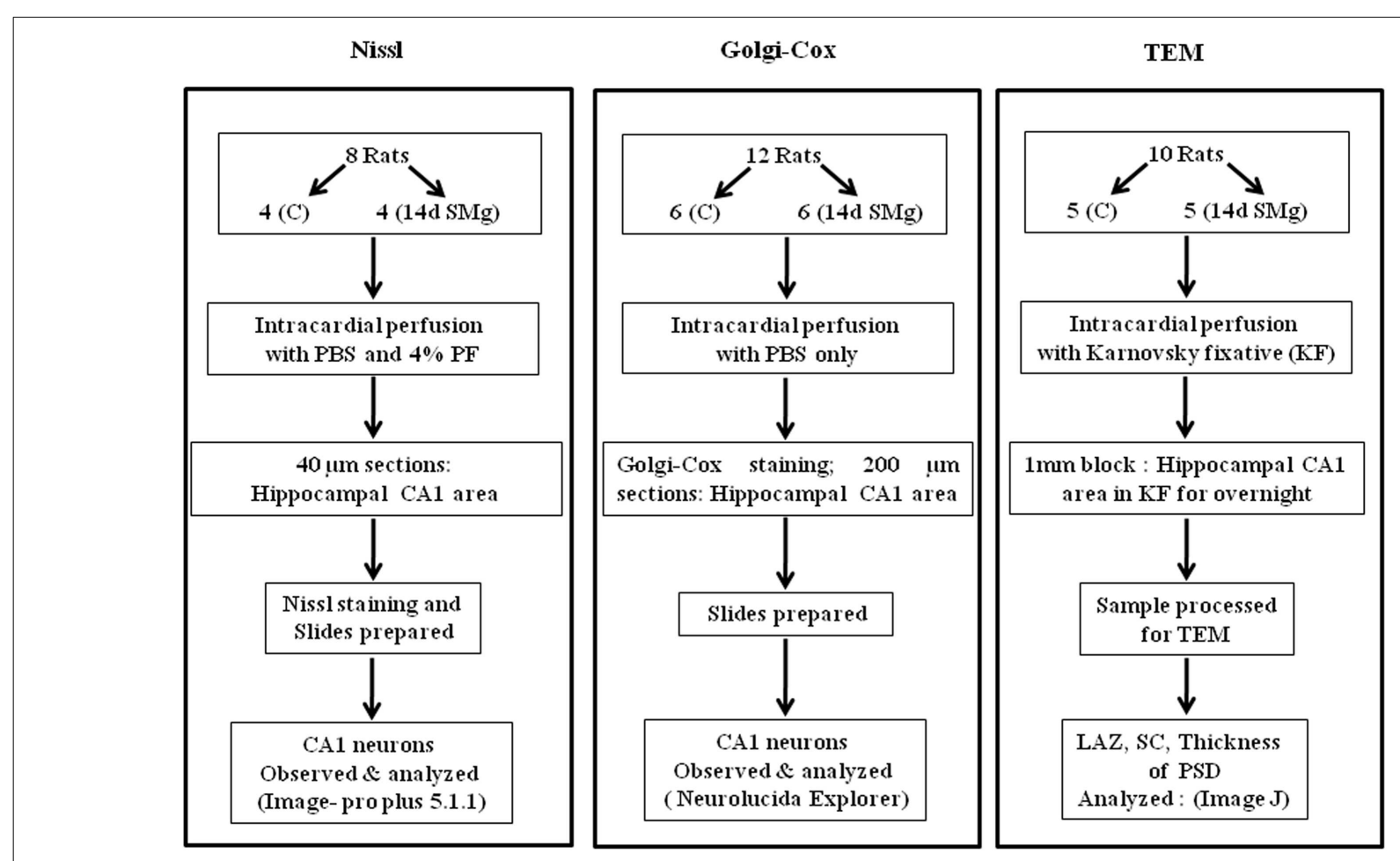

FIGURE 1 | Flow chart of the methods used for sample preparations in this study. Abbreviations: as in text. 
followed by freshly prepared Golgi-Cox solution (29). The freshly prepared Golgi-Cox solution contained 5 parts of 5\% potassium dichromate, 5 parts of $5 \%$ mercuric chloride, 4 parts of $5 \%$ potassium chromate in 10 parts of double distilled water. The brains were placed in a brain slicer (WPI, USA) and $5 \mathrm{~mm}$ thick coronal blocks containing the antero-posterior extension of hippocampus were taken out from each rat brain. Each tissue block was placed in separate cotton-lined dark colored glass bottle containing 25$30 \mathrm{ml}$ Golgi-Cox solution at $37^{\circ} \mathrm{C}$ for $72 \mathrm{~h}$ and slides were prepared as reported earlier $(28,30)$. In brief, $200 \mu \mathrm{m}$ thick coronal sections through hippocampus were cut using a vibratome (3000 series, Evergreen Blvd., St. Louis, MO, USA). The sections were rinsed, dehydrated with $50 \%$ of ethanol, and transferred into ammonia solution (3:1, 25\% ammonia: distilled water) for staining. The stained sections were rinsed, treated with $5 \%$ sodium thiosulfate in dark, rinsed in distilled water, dehydrated through increasing grades of alcohol (70, 80, 95\% of ethanol and 99\% of 1-butanol), cleared in toluene, and mounted in DPX on gelatin-coated slides. The slides were allowed to dry at room temperature for $72 \mathrm{~h}$ before observing under microscope for cytomorphological analysis. The control and experimental slides were coded and randomized to minimize bias.

The Golgi-impregnated pyramidal CA1 neurons from the hippocampus were readily identified by their characteristic triangular soma shape, apical dendritic extension toward the center, and many dendritic spines. The following criteria were used to select pyramidal neurons for analysis and reconstruction: (1) localization of a neuron in the CA1 area; (2) presence of untruncated dendrites; (3) full impregnation of the neurons; (4) relative isolation from neighboring impregnated neurons to avoid interference while analyzing. The spines were identified and counted based on the morphological criteria. Only protrusions perpendicular to the dendritic shaft that possessed a clear neck and bulbous head were counted.

To analyze effects of 14 days $\mathrm{SMg}$ on CA1 neurons, we carried out cytomorphological analysis of five to six neurons per animal in four to six sections. Thus, $28 \pm 2$ neurons in each experimental and control rats were traced $(1000 \times)$ and analyzed using a digital camera (MBF CX9000) attached to the microscope (Olympus BX51, Japan) using dedicated software Neurolucida 9 (MBF Biosciences, USA).

\section{TRANSMISSION ELECTRON MICROSCOPE METHOD}

In separate sets, transmission electron microscope (TEM) was used to evaluate the changes in SC, thickness of post PSD and LAZ of CA1 neurons from five control and five experimental rats. Anesthetized rats were intracardially perfused with $200 \mathrm{ml}$ of Karnovsky fixative. The brains were taken out, trimmed from all sides of expected hippocampal CA1 area to obtain approximately $1-1.5 \mathrm{~mm}^{3}$ pieces. All such samples containing the CA1 area were fixed overnight at $4^{\circ} \mathrm{C}$ in Karnovsky's fixative. Those tissues were then processed for TEM in Advanced Instrumentation Research Facility of our university. Samples were washed in $0.1 \mathrm{M}$ PB followed by post fixation in $1 \%$ osmium tetroxide in $0.1 \mathrm{M} \mathrm{PB}$. The samples were then washed, dehydrated in the ascending grades of acetone, cleared in toluene followed by infiltration, and embedded in araldite mixture (CY 212). The samples were labeled so that the analysis could be done unbiased to analyzer. One micrometer sections were cut using ultra microtome (Leica EMUC6, Austria) and stained with toluidine blue to identify the orientation of neurons. Ultra-thin sections $(80 \mathrm{~nm})$ were picked on meshed copper grids, and stained with uranyl acetate and lead citrate. The sections were viewed using microscope (TEM JEOL 2100F, Japan) and 1012 images of Gray's type-1 asymmetric synapse (magnification $30000 \times$ ) from each rat brain were captured at random for analysis. Synapses were identified by the presence of presynaptic and postsynaptic membrane thickening and the presence of synaptic vesicles in the presynaptic (terminal) zone. The width of the SC (mean of distances at three to four sites including the widest, intermediate, and least), the thickness of PSD at thickest part, and the LAZ were measured as reported earlier (31) using software Image J. Thus, on an average $60 \pm 5$ synapses were analyzed from five each of control and experimental rats.

\section{STATISTICAL ANALYSIS}

The data was expressed as mean \pm SEM. Data from experimental and control groups were statistically analyzed applying one-way analysis of variance (ANOVA) followed by Holm-Sidak test and $P \leq 0.05$ was considered significant using Sigma Stat software (Jandel Scientific, USA).

\section{RESULTS}

\section{NISSL-STAINING}

The mean $( \pm$ SEM) perimeter $[F(1,7)=39.89, P<0.001]$ and area $[F(1,7)=42.04, P<0.001]$ of 14 days SMg-treated CA1 neurons decreased significantly compared with control (Figure 2; Table 1). However, the mean FF $( \pm \operatorname{SEM})[F(1,7)=0.50$, $P=0.506]$ values in treated rats were comparable to that of the control values (Table 1).

\section{GOLGI-COX STAINING}

Golgi-stained traced neurons of control and 14 days SMg-treated rats were analyzed using Neurolucida Explorer. It was found that there were significant differences in various parameters as given below.

\section{Soma}

The mean $( \pm$ SEM $)$ perimeter $[F(1,11)=20.60, P<0.001]$ and area $[F(1,11)=46.33, P<0.001]$ of Golgi-stained 14 days SMgtreated CA1 neurons decreased significantly compared with that of the controls (Figures 2 and 3; Table 2); however, their FF values $[F(1,11)=0, P=1]$ were comparable to the controls.

\section{Basal dendrites}

The mean $( \pm$ SEM $)$ of total number of nodes $[F(1,11)=6.49$, $P=0.029]$, spines $[F(1,11)=11.80, P=0.006]$, and spine density (spine/micrometer) $[F(1,11)=16.78, P=0.002]$ of 14 days $\mathrm{SMg}$-exposed rats' basal dendrites increased significantly compared with that of respective control values (Figures 3 and 4; Table 2). Sholl analysis also showed more branching of basal dendrites in rats exposed to $\mathrm{SMg}$ (Figure 5). However, the mean basal dendritic length $[F(1,11)=3.13, P=0.107]$ of neurons of 14 days $\mathrm{SMg}$-exposed rats were comparable to that of respective controls (Figure 4; Table 2). 


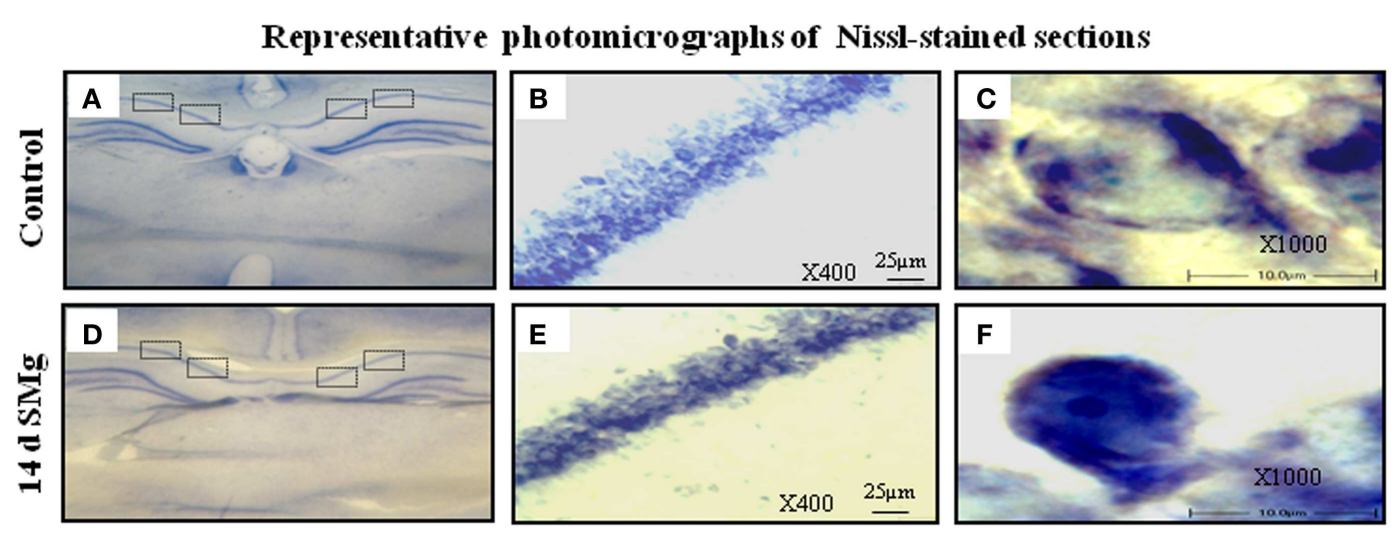

Effect of exposure to 14 days simulated microgravity on rat CA 1 neurons
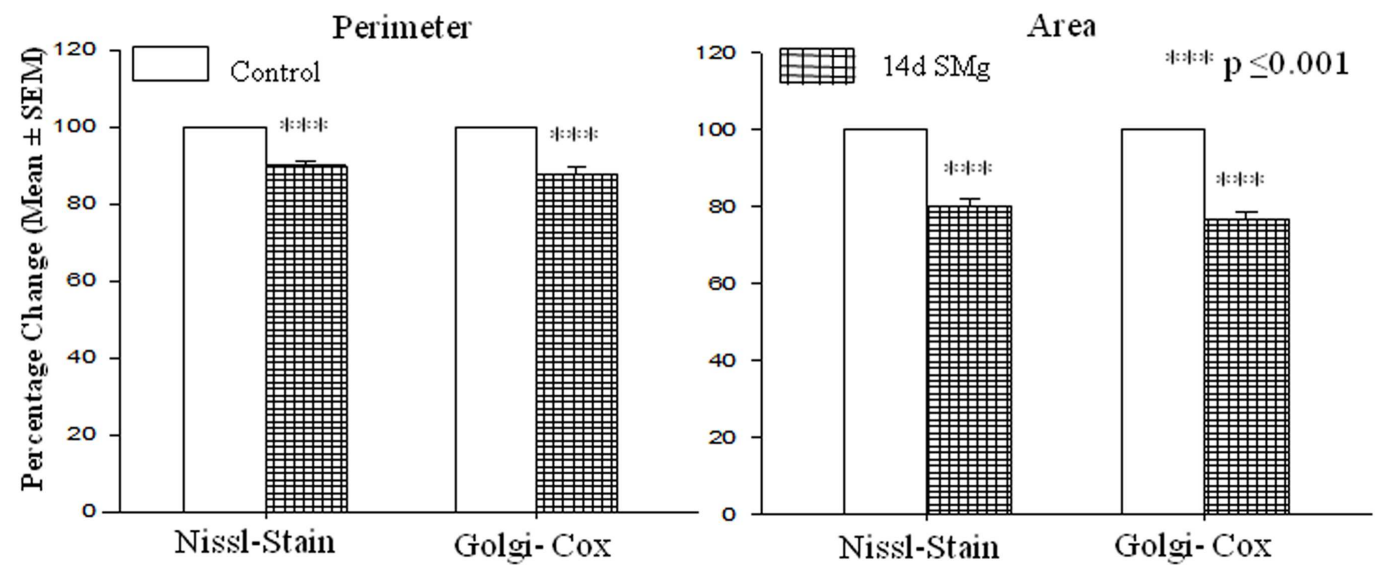

FIGURE 2 | Representative photomicrographs of Nissl-stained sections under control and 14 days $\mathrm{SMg}$ conditions are shown in this figure. (A,D) Representative complete sections having four blocks in each section. Neurons in each block were analyzed as described in the text. (B,E) $400 \times$ magnifications and CA1 hippocampal neurons under control and 14 days SMg conditions, respectively.
(C,F) Magnified representative single neurons from (B,E) at 1000× magnification. Histogram in the lower panel shows percentage changes in mean $( \pm$ SEM) perimeter and area of CA1 neurons in Nissl and Golgi-Cox-stained sections upon exposure to 14 days $\mathrm{SMg}$ condition as compared with control taken as $100 \% .{ }^{* *} P \leq 0.001$. Abbreviations: as in the text.
Table 1 | Nissl-stained CA1 neurons were analyzed after 14 days SMg and control conditions.

\begin{tabular}{|c|c|c|}
\hline Parameter of evaluation & $\begin{array}{c}\text { Controls } \\
N=4, n=850 \pm 50\end{array}$ & $\begin{array}{c}14 \text { Days SMg } \\
N=4, n=850 \pm 50\end{array}$ \\
\hline Area, $\mu \mathrm{m}^{2}$ (mean $\left.\pm \mathrm{SEM}\right)$ & $148.85 \pm 3.63$ & $\begin{array}{l}119.40 \pm 2.73 \\
* * * P<0.001\end{array}$ \\
\hline Perimeter, $\mu \mathrm{m}$ (mean \pm SEM) & $54.11 \pm 0.61$ & $\begin{array}{l}48.75 \pm 0.59 \\
* * * P<0.001\end{array}$ \\
\hline FF factor & $0.64 \pm 0.01$ & $\begin{array}{c}0.63 \pm 0.01 \\
P=0.51\end{array}$ \\
\hline
\end{tabular}

$N=$ number of experiments; $n=$ number of neurons studied.

${ }^{*}{ }^{*} P<0.001$ significantly different from control. Abbreviations: as in text.

\section{Apical dendrites}

The mean $( \pm$ SEM) number of nodes $[F(1,11)=8.38$, $P=0.016]$ of apical dendrites increased significantly after exposure to microgravity; while the mean $( \pm S E M)$ number of spines $[F(1,11)=4.178, P=0.068]$, spine density $[F(1$, $11)=2.685, P=0.132]$, and apical dendritic length $[F(1$, $11)=1.729, P=0.218]$ were comparable to respective controls (Figures 3 and 4; Table 2).

\section{Total (apical+ basal) dendrites}

Total dendrites showed similar pattern as that observed for basal dendrites. The mean $( \pm$ SEM $)$ number of nodes $[F(1,11)=18.24$, $P=0.002]$ and spines $[F(1,11)=12.69, P=0.005]$ as well as spine density $[F(1,11)=6.618, P=0.028]$ of total dendrites increased significantly after exposure to 14 days $\mathrm{SMg}$ (Figures 3 and 4; Table 2). However, the mean total dendritic length $[F(1,11)=4.03, P=0.072]$ of 14 days $\mathrm{SMg}$-treated neurons was comparable to that of respective controls (Figure 4; Table 2).

\section{TRANSMISSION ELECTRON MICROSCOPY}

There were significant decrease in SC $[F(1,9)=143.19, P<0.001]$ and $\operatorname{LAZ}[F(1,9)=35.05, P<0.001]$ of CA1 asymmetric synapses of 14 days $\mathrm{SMg}$-treated rats compared with respective control 


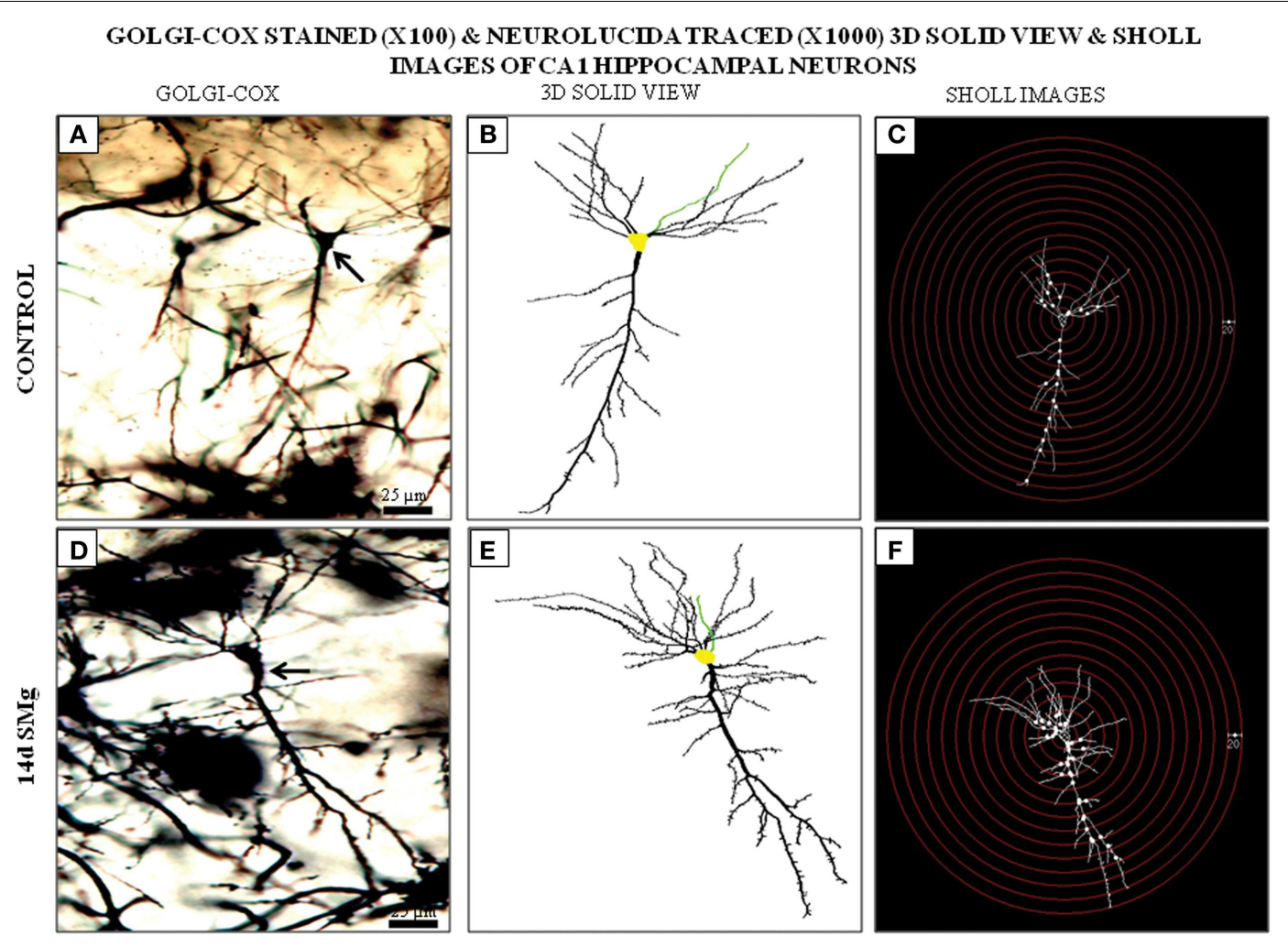

FIGURE 3 | Photomicrographs of Golgi-Cox-stained representative CA1 neurons (100x) from control $(A)$ and 14 days SMg-exposed (D) rats are shown (arrow). (B,E) 3-D-traced neurons $(\mathbf{1 0 0 0} \mathbf{x})$ in area marked on $(\mathbf{A}, \mathbf{D})$, respectively, using
Neurolucida 9 and Neurolucida explorer 9. (C,F) Sholl images of traced neurons in $(\mathbf{B}, \mathbf{E})$ respectively, having concentric radii of $20 \mu \mathrm{m}$. Fourteen days SMg showed more branching as compared with control. Abbreviations: as in the text. values; however thickness of $\operatorname{PSD}[F(1,9)=0.025, P=0.88]$ was comparable to that of its control values (Figure 6; Table 3).

\section{DISCUSSION}

In the present study, we observed that as compared with controls the CA1 neurons of the rats exposed to 14 days $\mathrm{SMg}$ showed decreased area, perimeter, SC, and LAZ; however, the number of nodes, spines, and spine density were increased. The length of dendrites, FF, and thickness of PSD were comparable to control. Thus, our results showed significant changes in CA1 neuronal cytomorphometry and their connectivity when rats were exposed to SMg.

We observed that upon exposure to SMg although in absolute terms the soma size (perimeter, area, and FF) of the Nissl-stained neurons were smaller compared with that of changes observed in Golgi-Cox-stained neurons, their relative percentage change (the control value taken as 100\%) was comparable (Figure 2). This is possibly because in Nissl stain molecules in the cytoplasm are stained, while in Golgi-Cox-stained neurons, the boundaries of the neurons are stained (32). Upon exposure to SMg, the soma FF values of CA1 neurons remained unaltered, which suggests that the decrease in area was proportional to the decrease in square of the perimeter of the cells as reported earlier (26). Such is possible in case of neurons having smooth surface and regular shape, i.e., without possessing significant number of somatic protrusions, appendages, or spines. This view may be supported by the fact that in our Golgi-Cox-stained sections, we observed that the cell bodies of the CA1 neurons possess very few somatic protrusions, appendages, and spines. Thus, our findings suggest that hippocampal CA1 neurons are more vulnerable, as reflected by alterations in their sizes, upon exposure to $\mathrm{SMg}$ than that of other rough surfaced neurons (26).

The active zones in the presynaptic terminals possess various types of SNARE (soluble $N$-ethyl-maleimide-sensitive factor attachment protein receptor) proteins (33), which mediate synaptic vesicle fusion with the presynaptic terminal membrane and exocytosis of neurotransmitters (34). Thus, our finding that $\mathrm{SMg}$ exposure induced down regulation of SNARE proteins may be interpreted as there would be reduced release of neurotransmitters in the rat brain after SMg exposure (35), which then would affect brain functions including behavior. Microgravity exposure-associated down regulation of many SNARE proteins in hippocampal neurons as has been reported earlier $(2,36)$ and reduced LAZ as observed in this study support our interpretation. Relative reduction of activation of CA1 neurons would cause reduced influx and reduced concentration of $\mathrm{Na}^{+}$inside the neurons (37) resulting in exosmosis (38) and reduction in the size of CA1 neurons after exposure to 14 days SMg as discussed above.

Gravitational force acts in a particular plane of orientation and defines the spatial environment, which however, changes upon 
Table 2 | Golgi-Cox-stained CA1 neurons were analyzed after 14 days $\mathrm{SMg}$ and control conditions.

\begin{tabular}{|c|c|c|}
\hline Parameter of evaluation & $\begin{array}{l}\text { Controls } \\
\text { (mean } \pm \text { SEM) } \\
N=6, n=28 \pm 2\end{array}$ & $\begin{array}{c}14 \text { Days SMg } \\
\text { (mean } \pm \text { SEM) } \\
N=6, n=28 \pm 2\end{array}$ \\
\hline Perimeter ( $\mu \mathrm{m})$ & $59.44 \pm 1.24$ & $\begin{array}{c}52.18 \pm 1.01 \\
* * * P<0.001\end{array}$ \\
\hline Area $\left(\mu \mathrm{m}^{2}\right)$ & $214.61 \pm 6.16$ & $\begin{array}{l}165.13 \pm 3.86 \\
* * * P<0.001\end{array}$ \\
\hline FF factors & $0.77 \pm 0.02$ & $\begin{array}{c}0.77 \pm 0.02 \\
P=1\end{array}$ \\
\hline Nodes dendrite (D) & $10.35 \pm 0.60$ & $\begin{array}{c}12.68 \pm 0.69 \\
{ }^{*} P=0.029\end{array}$ \\
\hline Nodes apical dendrite (AD) & $13.46 \pm 0.56$ & $\begin{array}{c}16.48 \pm 0.88 \\
* P=0.016\end{array}$ \\
\hline Spines (D) & $206.77 \pm 13.62$ & $\begin{array}{c}283.96 \pm 17.87 \\
{ }^{*} P=0.006\end{array}$ \\
\hline Spines (AD) & $178.96 \pm 9.31$ & $\begin{array}{c}218.92 \pm 17.19 \\
P=0.068\end{array}$ \\
\hline Total length $(\mathrm{D})(\mu \mathrm{m})$ & $1099.91 \pm 60.61$ & $\begin{array}{c}1289.08 \pm 88.08 \\
P=0.107\end{array}$ \\
\hline Total length (AD) $(\mu \mathrm{m})$ & $1301 \pm 45.50$ & $\begin{array}{c}1424.24 \pm 81.94 \\
P=0.219\end{array}$ \\
\hline $\begin{array}{l}\text { Spine density (D) } \\
\text { Spine per } \mu \mathrm{m}\end{array}$ & $0.19 \pm 0.007$ & $\begin{array}{c}0.24 \pm 0.01 \\
* *=0.002\end{array}$ \\
\hline Spine density (AD) & $0.14 \pm 0.007$ & $\begin{array}{c}0.16 \pm 0.01 \\
P=0.132\end{array}$ \\
\hline Nodes $(D+A D)$ & $23.81 \pm 0.85$ & $\begin{array}{l}29.16 \pm 0.92 \\
* * P=0.002\end{array}$ \\
\hline Spines $(D+A D)$ & $385.73 \pm 19.03$ & $\begin{array}{c}502.88 \pm 26.81 \\
\quad * *=0.005\end{array}$ \\
\hline Total length $(D+A D)(\mu m)$ & $2400.95 \pm 73.61$ & $\begin{array}{c}2713.31 \pm 137.06 \\
P=0.072\end{array}$ \\
\hline Spine density $(D+A D)$ & $0.16 \pm 0.006$ & $\begin{array}{l}0.19 \pm 0.01 \\
{ }^{*} P=0.028\end{array}$ \\
\hline
\end{tabular}

$N=$ number of experiments; $n=$ number of neurons studied.

${ }^{* *} P \leq 0.001$ or ${ }^{* *} P \leq 0.01$ or ${ }^{*} P \leq 0.05$ significantly different from control.

14 days SMg, 14 days simulated microgravity; $A D$, apical dendrites; $D$, basal dendrites.

exposure to microgravity. Under our experimental $\mathrm{SMg}$ condition, afferent flow from the hind-limbs decreases due to unloading. In order to compensate for the lack of afferent flow, hippocampal neurons may respond with the creation of new synapses and rearrangements of neuronal circuits (1). Thus, it is possible that the cytomorphometric changes, i.e., increase in number of nodes, spine, and spine density could be compensatory effects caused by SMg. However, basal and apical dendrites did not show similar responses; basal dendrites showed significant increase in number of nodes, spine, and spine density, while apical dendrites were comparable to respective controls. Previous study showed differential propensity for long-term potentiation (LTP) at basal and apical dendritic synapse of CA1 neurons (39). They concluded that, "basal dendritic potentiation would increase and decrease relatively quickly, while the apical dendritic LTP would occur only after a certain degree of disinhibition." Thus, in our study, the basal dendrites were modulated differentially than that of apical dendrites after 14 days SMg, which is likely to have bearing with information processing by the neurons. We cannot comment on whether these changes are specific to hippocampal CA1 neurons, or are generalized phenomena, which need further study.

Visualization of dendritic arborization has bearing on staining methods like intracellular Nissl-staining or Golgi staining of neurons. The latter staining appears to show decreased dendritic visualization as compared with intracellular staining of hippocampal CA1 neurons and our findings on dendritic length are consistent with the results of Golgi-stained hippocampal CA1 neurons as reported earlier (40-49). Although classical Golgi method has a number of challenges for quantitative evaluation of neuronal morphology, it has the merit of providing a broad overview of the neuronal characteristics for comparative analysis. Therefore, our results may not be comparable with intracellular staining but they are sufficient for relative understanding of neuronal morphology. Further, as it is not possible that all neurons are evenly cut during sectioning, we have considered only those Nissl-stained selected neurons where nuclear boundaries were clearly visible. We were also aware that cytoplasmic staining does not allow a critical outline of cytoplasmic membrane. Hence, to minimize sampling error, we estimated a large number of randomly selected neurons $(850 \pm 50)$ across the hippocampal CA1 area (Figure 2) from four rats each of control and experimental groups. These measures served to significantly overcome the limitations associated to Nissl-staining while analyzing area and perimeter of neurons. As the intra-group data were comparable, the values were pooled for comparative analysis between control and experimental groups and determining the statistical significance.

Gravity influences most physiological processes (50). During space travel, astronauts are exposed to low gravity, which could affect neuronal cytomorphology resulting in changes in normal brain functions. Since there are significant limitations in conducting studies in space, including that of cost and opportunities, earth-based simulation studies have been designed to investigate the physiological responses to weightlessness. For example, clinostats for plants and non-motile cells (51), head-down bed rest for humans (52), water immersion for humans (53), HLS model for rodents $(22,23)$ have been used. Despite some shortcomings, in the absence of availability of better model for such studies, rodent HLS model has been widely accepted to simulate microgravity condition comparable to induced during space flight and to study its effect on physiological processes occurring due to unloading (22).

Hippocampal neurons are highly sensitive to stress (54) and atrophy of the thymus, adrenal hypertrophy, and corticosterone levels are indicators of stress. Accordingly, based on changes in these and additional parameters, the National Aeronautics and Space Administration (NASA) Ames Research Centre (ARC) Animal Care has approved HLS rat model for such studies. Although there were some disagreements on HLS-associated changes in adrenal hypertrophy (55) and corticosterone level (56-58) up to 7 day exposure to $\mathrm{SMg}$, these parameters were comparable to normal on longer exposure; hence, we used longer (14 days exposure to $\mathrm{SMg}$ ) paradigm as reported earlier (22). In our experiment during initial exposure to HLS, we observed fluctuations in body 


\section{Effect of 14days simulated microgravity on rat CA1 neurons}

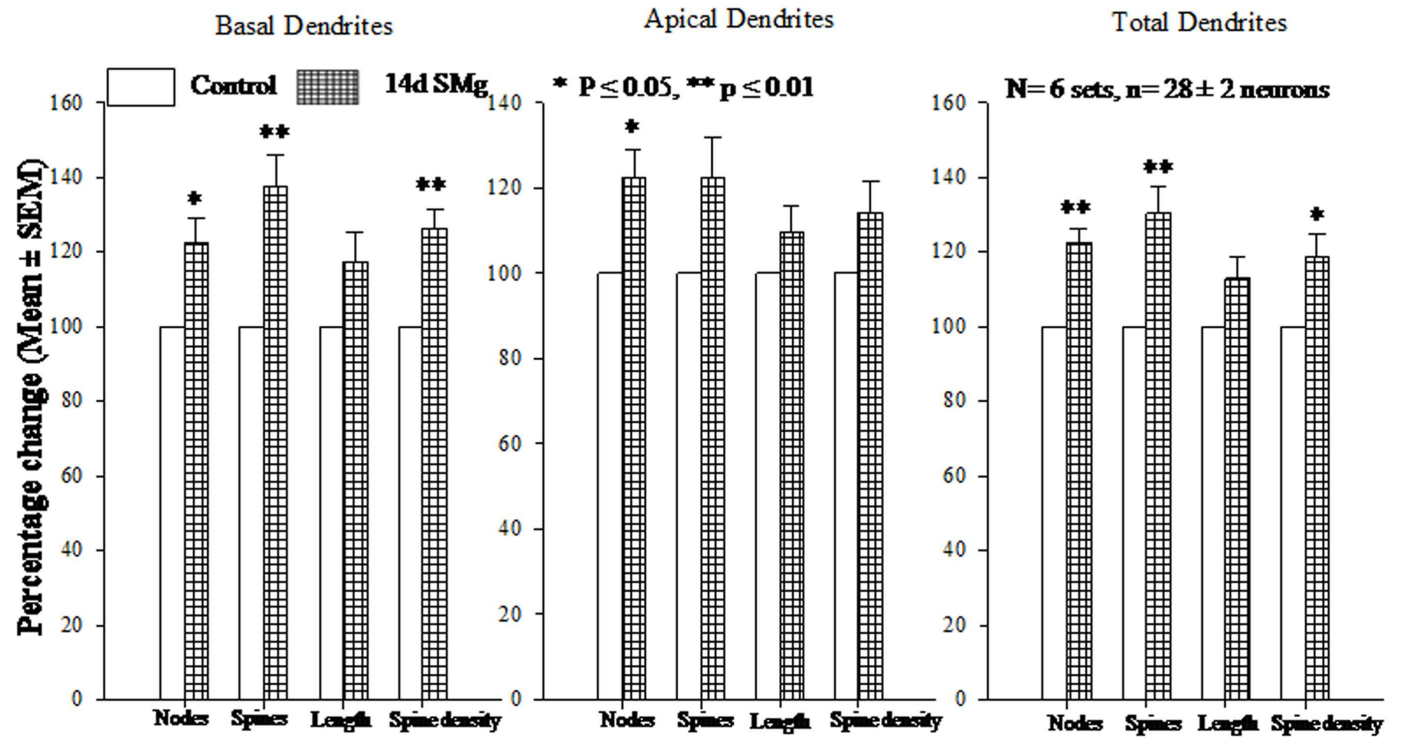

FIGURE 4 | Histograms showing percentage changes in mean ( \pm SEM) number of nodes, spines, dendritic length, and spine density of traced Golgi-Cox-stained CA1 neurons upon exposure to 14 days SMg condition as compared with its control taken as $100 \%$ are represented by bars. ${ }^{*} P \leq 0.01 ;{ }^{*} P \leq 0.05$ significantly different from control. $N=$ total number of sets, $n=$ total number of neurons studied. Abbreviations: as in text.

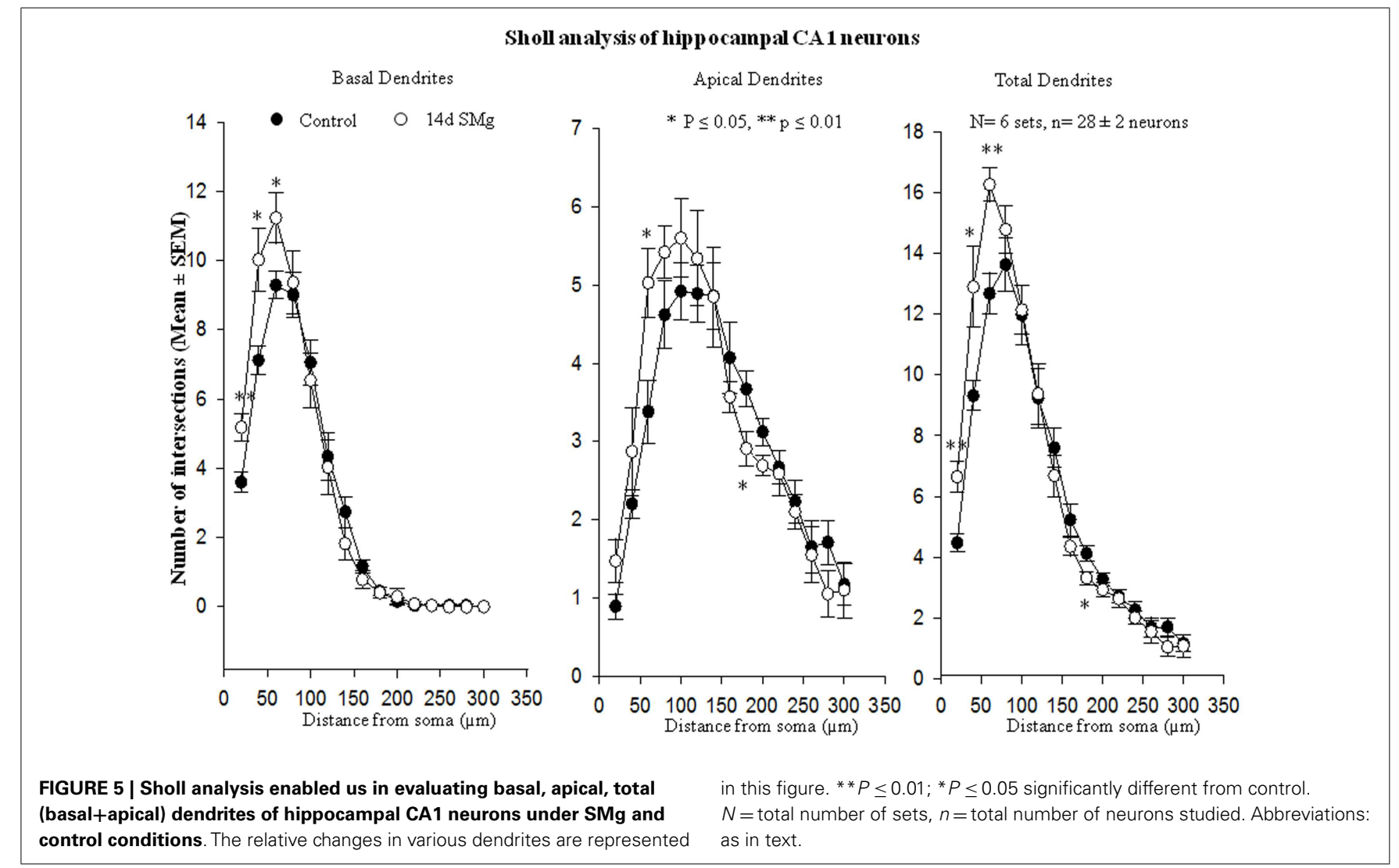


Electromicrograph of hippocampal CAl asymmetric synapse
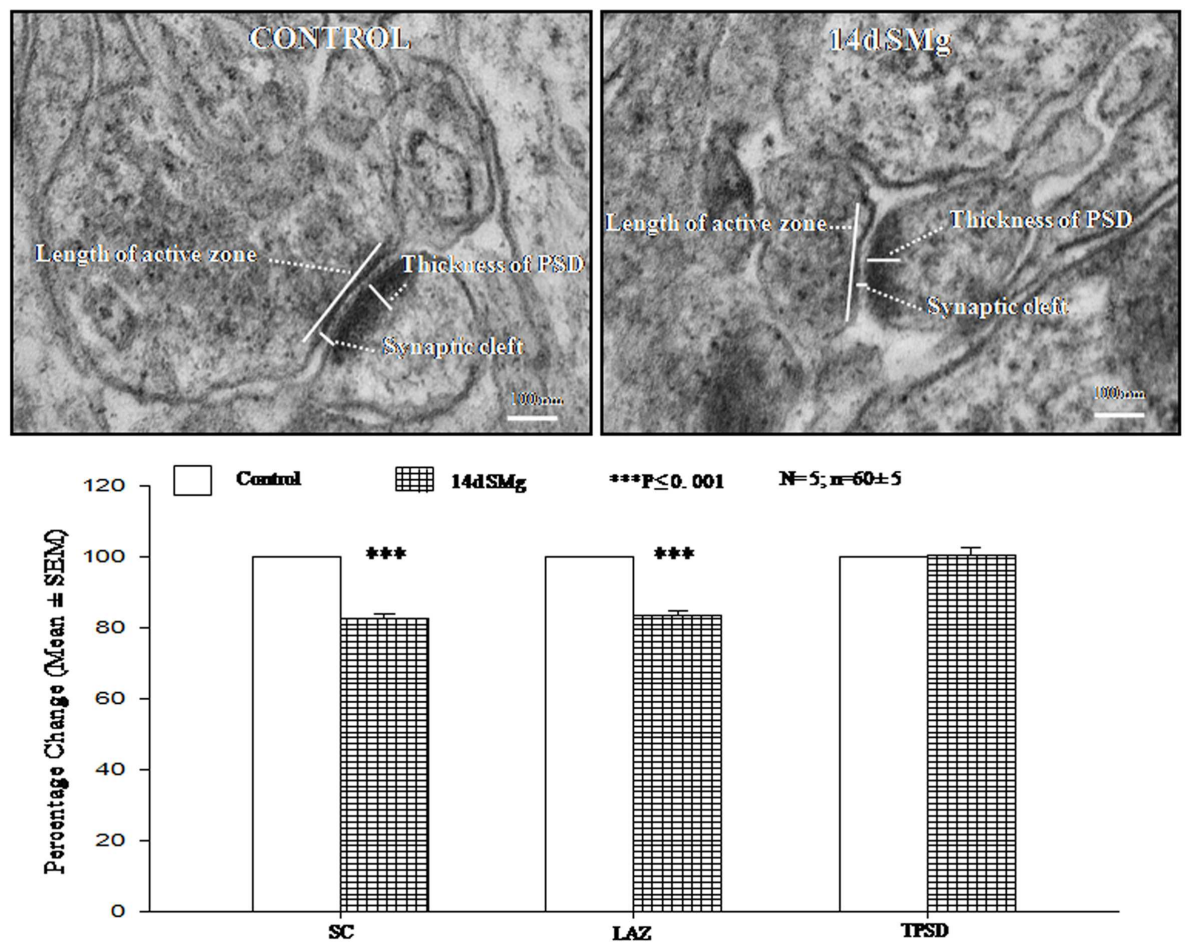

FIGURE 6 | Electron micrograph showing the ultrastructural features of synapses in CA1 area. The synaptic cleft, length of active zone, and thickness of PSD are shown in the figure. Lower panel histogram shows percentage changes in mean ( \pm SEM) SC,
LAZ, and TPSD of CA1 neurons upon exposure of rats to 14 days SMg condition as compared with control taken as $100 \% . N=$ total number of sets, $n=$ total number of synapses studied. Abbreviations: as in the text.
Table 3 | Synapses were selected according to the criteria of Gray's type-1 synapse.

\begin{tabular}{lcc}
\hline Parameter of evaluation & $\begin{array}{c}\text { Controls } \\
(\boldsymbol{N}=\mathbf{5}, \boldsymbol{n}=\mathbf{6 0} \pm \mathbf{5})\end{array}$ & $\begin{array}{c}\text { 14 Days SMg } \\
(\boldsymbol{N}=\mathbf{5}, \boldsymbol{n}=\mathbf{6 0} \pm \mathbf{5})\end{array}$ \\
\hline SC (mean \pm SEM) (nm) & $25.41 \pm 0.14$ & $21.01 \pm 0.34$ \\
& & $* * * 0.001$ \\
LAZ (mean \pm SEM) (nm) & $267.82 \pm 6.06$ & $223.52 \pm 4.39$ \\
& & $* * P<0.001$ \\
Thickness of PSD & $42.64 \pm 0.86$ & $42.84 \pm 0.92$ \\
(mean \pm SEM) (nm) & & $P=0.88$ \\
\hline
\end{tabular}

Selected CA1 synapses were analyzed after 14 days SMg and control conditions. $N=$ number of experiments; $n=$ number of synapses studied.

${ }^{* *} P<0.001$ significantly different from control. Abbreviations: as in text.

weight, stabilized by the 14th day, which was possibly an adaptive response to the new environment. The results were specific to $\mathrm{SMg}$ because control rats maintained in normal cages in the same room were unaffected. Notwithstanding, although our findings are suggestive, further studies are needed to understand the effects of chronic exposure to SMg.

Mammalian central nervous system has evolved within earth's 1-g gravitational field and exposure to altered gravity may lead to cognitive and learning deficits $(6,8,9)$. Exposure to SMg has been reported to impair learning and memory in rodents $(8,17)$, which is generally consistent with previous studies and space flight data $(6,59,60)$. Relatively very few studies have investigated the effects of exposure to altered gravity on cognitive functions and whatever little are available, the results are inconclusive (61, 62); also, we have very little knowledge about their mechanism of action. It has been reported that initial 3 weeks in space mission and first 2 weeks after returning from prolonged space flight were critical for changes in learning and memory (63). In our case, 14 days exposure to $\mathrm{SMg}$ resulted in morphological differences in the CA1 neurons of rats, which could be likely indication of early cytomorphological changes for the induction and expression of future behavioral changes. The microgravity exposure-associated impairment of cognitive functions are likely to be dependent on the duration of exposure and the effects varied depending on predisposition, rate of recovery, and degree of adaptation. Previous studies showed loss of dendritic spines after suffering from cerebral stroke $(64,65)$. Subject to confirmation, on a positive note, based on our findings of growth of dendritic spines after exposure of $\mathrm{SMg}$, as a possible therapy, we put forward a testable proposition that stroke patients may be exposed to controlled-SMg for growth of nodes, spines, dendrites for better and faster recovery. Also, since we are fast moving toward space travel (mars, moon missions, etc.), health of the space crew members is a major concern; 
our results may be useful to explore countermeasures and design effective prevention of the astronauts exposed to microgravity.

\section{CONCLUSION}

We observed that hippocampal CA1 neurons of rats exposed to 14 days SMg although showed impaired cytomorphological characteristics and connectivity, their arborizations were increased. The latter could be a compensatory effect, which under specific conditions, e.g., for recovery in brain stroke patients, may be beneficial. Our results add to the limited knowledge available in the field and may be useful to explore countermeasures and to design effective prevention of symptoms especially in astronauts expressing deficits in cognitive functions; for which we lack detail study.

\section{AUTHORS CONTRIBUTION}

Amit Ranjan collected and analyzed the data as well as participated in preparing this manuscript; Jitendra Behari extended help while planning the study. Birendra N. Mallick planned the study, arranged funds, and wrote the manuscript. All authors have read and approved the final manuscript.

\section{ACKNOWLEDGMENTS}

Amit Ranjan received fellowship from Council of Scientific and Industrial Research. Research funding from Department of Science and Technology, FIST, DST-PURSE, UPOE, and J.C. Bose Fellowship to Birendra N. Mallick are acknowledged. TEM was carried out at the AIRF, JNU.

\section{REFERENCES}

1. Vazquez ME. Neurobiological problems in long-term deep space flights. $A d v$ Space Res (1998) 22(2):171-83. doi:10.1016/S0273-1177(98)80009-4

2. Sarkar P, Sarkar S, Ramesh V, Hayes BE, Thomas RL, Wilson BL, et al. Proteomic analysis of mice hippocampus in simulated microgravity environment. J Proteome Res (2006) 5(3):548-53. doi:10.1021/pr050274r

3. Sarkar P, Sarkar S, Ramesh V, Kim H, Barnes S, Kulkarni A, et al. Proteomic analysis of mouse hypothalamus under simulated microgravity. Neurochem Res (2008) 33(11):2335-41. doi:10.1007/s11064-008-9738-1

4. Frigeri A, Iacobas DA, Iacobas S, Nicchia GP, Desaphy JF, Camerino DC, et al. Effect of microgravity on gene expression in mouse brain. Exp Brain Res (2008) 191(3):289-300. doi:10.1007/s00221-008-1523-5

5. Belichenko PV. Quantitative analysis of dendritic spines of pyramidal neurons in the layers of the sensorimotor cortex of rats exposed to the Cosmos-1667 biosputnik. Biull Eksp Biol Med (1988) 105(6):736-8.

6. Manzey D, Lorenz B. Mental performance during short-term and long-term spaceflight. Brain Res Rev (1998) 28(1-2):215-21. doi:10.1016/S0165-0173(98) 00041-1

7. Cao XS, Sun XQ, Zhang S, Wang B, Wu YH, Liu TS, et al. Acceleration aftereffects on learning and memory in rats: $+10 \mathrm{Gz}$ or $+6 \mathrm{Gz}$ for $3 \mathrm{~min}$. Neurosci Lett (2007) 413(3):245-8. doi:10.1016/j.neulet.2006.11.055

8. Wu DW, Shen XY, Dong Q, Wang SP, Cheng ZH, Zhang SJ. Effects of tail suspension on learning and memory function of mice. Space Med Med Eng (Beijing) (2000) 13(4):244-8.

9. Reschke MF, Bloomberg JJ, Harm DL, Paloski WH, Layne C, McDonald V. Posture, locomotion, spatial orientation, and motion sickness as a function of space flight. Brain Res Rev (1998) 28(1-2):102-17. doi:10.1016/S0165-0173(98) 00031-9

10. Temple MD, Kosik KS, Steward O. Spatial learning and memory is preserved in rats after early development in a microgravity environment. Neurobiol Learn Mem (2002) 78(2):199-216. doi:10.1006/nlme.2001.4049

11. Benke T, Koserenko O, Watson NV, Gerstenbrand F. Space and cognition: the measurement of behavioral functions during a 6-day space mission. Aviat Space Environ Med (1993) 64(5):376-9.
12. Manzey D, Lorenz B, Schiewe A, Finell G, Thiele G. Behavioral aspects of human adaptation to space: analyses of cognitive and psychomotor performance in space during an 8-day space mission. Clin Investig (1993) 71(9):725-31. doi:10.1007/BF00209727

13. Manzey D, Lorenz B, Schiewe A, Finell G, Thiele G. Dual-task performance in space: results from a single-case study during a short-term space mission. Hum Factors (1995) 37(4):667-81. doi:10.1518/001872095778995599

14. Schiflett S, Eddy D, Schlegel R, French J, Shehab R. Performance Assessment Workstation (PAWS). Final science report to NASA (1995).

15. Chen Y, Rex CS, Rice CJ, Dube CM, Gall CM, Lynch G, et al. Correlated memory defects and hippocampal dendritic spine loss after acute stress involve corticotropin-releasing hormone signaling. Proc Natl Acad Sci U S A (2010) 107(29):13123-8. doi:10.1073/pnas.1003825107

16. Hwang IK, Yoo KY, Jung BK, Cho JH, Kim DH, Kang TC, et al. Correlations between neuronal loss, decrease of memory, and decrease expression of brain-derived neurotrophic factor in the gerbil hippocampus during normal aging. Exp Neurol (2006) 201(1):75-83. doi:10.1016/j.expneurol.2006. 02.129

17. Sun XQ, Xu ZP, Zhang S, Cao XS, Liu TS. Simulated weightlessness aggravates hypergravity-induced impairment of learning and memory and neuronal apoptosis in rats. Behav Brain Res (2009) 199(2):197-202. doi:10.1016/j.bbr. 2008.11.035

18. Wyllie AH, Kerr JF, Currie AR. Cell death: the significance of apoptosis. Int Rev Cytol (1980) 68:251-306. doi:10.1016/S0074-7696(08)62312-8

19. Biswas S, Mishra P, Mallick BN. Increased apoptosis in rat brain after rapid eye movement sleep loss. Neuroscience (2006) 142(2):315-31. doi:10.1016/j. neuroscience.2006.06.026

20. Tsien JZ, Huerta PT, Tonegawa S. The essential role of hippocampal CA1 NMDA receptor-dependent synaptic plasticity in spatial memory. Cell (1996) 87(7):1327-38. doi:10.1016/S0092-8674(00)81827-9

21. Morey ER. Spaceflight and bone turnover - correlation with a new rat model of weightlessness. Bioscience (1979) 29(3):168-72. doi:10.2307/1307797

22. Morey-Holton ER, Globus RK. Hindlimb unloading rodent model: technical aspects. J Appl Physiol (2002) 92(4):1367-77. doi:10.1152/japplphysiol.00969. 2001

23. Prakash D, Behari J. Synergistic role of hydroxyapatite nanoparticles and pulsed electromagnetic field therapy to prevent bone loss in rats following exposure to simulated microgravity. Int J Nanomedicine (2009) 4:133-44. doi:10.1109/AMTA.2008.4763233

24. Paxinos G, Watson C. The Rat Brain in Stereotaxic Coordinates. New York: Academic Press (1998).

25. Majumdar S, Mallick BN. Cytomorphometric changes in rat brain neurons after rapid eye movement sleep deprivation. Neuroscience (2005) 135(3):679-90. doi:10.1016/j.neuroscience.2005.06.085

26. Ranjan A, Biswas S, Mallick BN. Cytomorphometric changes in the dorsal raphe neurons after rapid eye movement sleep deprivation are mediated by noradrenalin in rats. Behav Brain Funct (2010) 6:62. doi:10.1186/1744-90816-62

27. Jinno S, Kinukawa N, Kosaka T. Morphometric multivariate analysis of GABAergic neurons containing calretinin and neuronal nitric oxide synthase in the mouse hippocampus. Brain Res (2001) 900(2):195-204. doi:10.1016/S00068993(01)02292-2

28. Ranjan A, Mallick BN. A modified method for consistent and reliable Golgi-Cox staining in significantly reduced time. Front Neurol (2010) 1:157. doi:10.3389/ fneur.2010.00157

29. Rutledge LT, Duncan J, Beatty N. A study of pyramidal cell axon collaterals in intact and partially isolated adult cerebral cortex. Brain Res (1969) 16(1):15-22. doi:10.1016/0006-8993(69)90082-1

30. Ranjan A, Mallick BN. Differential staining of glia and neurons by modified Golgi-Cox method. J Neurosci Methods (2012) 209(2):269-79. doi:10.1016/j. jneumeth.2012.06.023

31. Guldner FH, Ingham CA. Increase in postsynaptic density material in optic target neurons of the rat suprachiasmatic nucleus after bilateral enucleation. Neurosci Lett (1980) 17(1-2):27-31. doi:10.1016/0304-3940(80)90056-7

32. Pilati N, Barker M, Panteleimonitis S, Donga R, Hamann M. A rapid method combining Golgi and Nissl staining to study neuronal morphology and cytoarchitecture. J Histochem Cytochem (2008) 56(6):539-50. doi:10.1369/jhc.2008. 950246 
33. Zhai RG, Bellen HJ. The architecture of the active zone in the presynaptic nerve terminal. Physiology (Bethesda) (2004) 19:262-70. doi:10.1152/physiol.00014. 2004

34. Jahn R, Scheller RH. SNAREs - engines for membrane fusion. Nat Rev Mol Cell Biol (2006) 7(9):631-43. doi:10.1038/nrm2002

35. Bonanno G, Giambelli R, Raiteri L, Tiraboschi E, Zappettini S, Musazzi L, et al. Chronic antidepressants reduce depolarization-evoked glutamate release and protein interactions favoring formation of SNARE complex in hippocampus. J Neurosci (2005) 25(13):3270-9. doi:10.1523/JNEUROSCI.5033-04.2005

36. Hu G, Ma Y, Zhou Y, Cai D, Xiao S, Deng Y. SNAREs-related pathways in rat brains under simulated microgravity environment. Bioinformatics and Biomedical Engineering, ICBBE 2009 3rd International Conference. Beijing: IEEE (2009). p. 1-4. doi:10.1109/ICBBE.2009.5163409

37. Schwartz JH. Neurotransmitters. In: Kandel ER, Schwartz JH, Jessell TH, editors. Principles of Neural Sciences. New York: McGraw-Hill (2000). 284 p.

38. Bortner CD, Hughes FM Jr, Cidlowski JA. A primary role for $\mathrm{K}+$ and $\mathrm{Na}+$ efflux in the activation of apoptosis. J Biol Chem (1997) 272(51):32436-42. doi:10.1074/jbc.272.51.32436

39. Kaibara T, Leung LS. Basal versus apical dendritic long-term potentiation of commissural afferents to hippocampal CA1: a current-source density study. J Neurosci (1993) 13(6):2391-404.

40. Minkwitz HG, Holz L. The ontogenetic development of pyramidal neurons in the hippocampus (CA1) of the rat. J Hirnforsch (1975) 16(1):37-54.

41. Minkwitz HG. Development of neuronal structure in the hippocampus during pre- and post-natal ontogenesis in the albino rat. III. Morphometric determination of ontogenetic changes in dendrite structure and spine distribution on pyramidal neurons (CA1) of the hippocampus. J Hirnforsch (1976) 17(3): 255-75.

42. Amaral DG, Ishizuka N, Claiborne B. Neurons, numbers and the hippocampal network. Prog Brain Res (1990) 83:1-11. doi:10.1016/S0079-6123(08)61237-6

43. Ishizuka N, Cowan WM, Amaral DG. A quantitative analysis of the dendritic organization of pyramidal cells in the rat hippocampus. J Comp Neurol (1995) 362(1):17-45. doi:10.1002/cne.903620103

44. Pyapali GK, Sik A, Penttonen M, Buzsaki G, Turner DA. Dendritic properties of hippocampal CA1 pyramidal neurons in the rat: intracellular staining in vivo and in vitro. J Comp Neurol (1998) 391(3):335-52. doi:10.1002/(SICI)10969861(19980216)391:3<335::AID-CNE4>3.0.CO;2-2

45. Altemus KL, Lavenex P, Ishizuka N, Amaral DG. Morphological characteristics and electrophysiological properties of CAl pyramidal neurons in macaque monkeys. Neuroscience (2005) 136(3):741-56. doi:10.1016/j.neuroscience.2005. 07.001

46. Alonso M, Medina JH, Pozzo-Miller L. ERK1/2 activation is necessary for BDNF to increase dendritic spine density in hippocampal CA1 pyramidal neurons. Learn Mem (2004) 11(2):172-8. doi:10.1101/lm.67804

47. Brocca ME, Pietranera L, Beauquis J, De Nicola AF. Estradiol increases dendritic length and spine density in CA1 neurons of the hippocampus of spontaneously hypertensive rats: a Golgi impregnation study. Exp Neurol (2013) 247C:158-64. doi:10.1016/j.expneurol.2013.04.007

48. Zhao YD, Ou S, Cheng SY, Xiao Z, He WJ, Zhang JH, et al. Dendritic development of hippocampal CA1 pyramidal cells in a neonatal hypoxia-ischemia injury model. J Neurosci Res (2013) 91(9):1165-73. doi:10.1002/jnr.23247

49. Silva-Gomez AB, Rojas D, Juarez I, Flores G. Decreased dendritic spine density on prefrontal cortical and hippocampal pyramidal neurons in postweaning social isolation rats. Brain Res (2003) 983(1-2):128-36. doi:10.1016/S0006-8993(03) 03042-7

50. Morey-Holton E, Globus RK, Kaplansky A, Durnova G. The hindlimb unloading rat model: literature overview, technique update and comparison with space flight data. Adv Space Biol Med (2005) 10:7-40. doi:10.1016/S1569-2574(05) 10002-1
51. Klaus DM. Clinostats and bioreactors. Gravit Space Biol Bull (2001) 14(2):55-64. 52. Styf JR, Hutchinson K, Carlsson SG, Hargens AR. Depression, mood state, and back pain during microgravity simulated by bed rest. Psychosom Med (2001) 63(6):862-4. doi:10.1097/00006842-200111000-00002

53. Shiraishi M, Schou M, Gybel M, Christensen NJ, Norsk P. Comparison of acute cardiovascular responses to water immersion and head-down tilt in humans. J Appl Physiol (2002) 92(1):264-8.

54. Kim JJ, Diamond DM. The stressed hippocampus, synaptic plasticity and lost memories. Nat Rev Neurosci (2002) 3(6):453-62. doi:10.1038/nrn849

55. Deavers DR, Musacchia XJ, Meininger GA. Model for antiorthostatic hypokinesia: head-down tilt effects on water and salt excretion. J Appl Physiol (1980) 49(4):576-82.

56. Halloran BP, Bikle DD, Cone CM, Morey-Holton E. Glucocorticoids and inhibition of bone formation induced by skeletal unloading. Am J Physiol (1988) 255(6 Pt 1):E875-9.

57. Steffen JM, Musacchia XJ. Disuse atrophy, plasma corticosterone, and muscle glucocorticoid receptor levels. Aviat Space Environ Med (1987) 58(10): 996-1000.

58. Ortiz RM, Wang TJ, Wade CE. Influence of centrifugation and hindlimb suspension on testosterone and corticosterone excretion in rats. Aviat Space Environ Med (1999) 70(5):499-504.

59. Fowler B, Comfort D, Bock O. A review of cognitive and perceptual-motor performance in space. Aviat Space Environ Med (2000) 71(Suppl 9):A66-8.

60. Knierim JJ, McNaughton BL, Poe GR. Three-dimensional spatial selectivity of hippocampal neurons during space flight. Nat Neurosci (2000) 3(3):209-10. doi: $10.1038 / 72910$

61. Porte Y, Morel JL. Learning on Jupiter, learning on the Moon: the dark side of the G-force. Effects of gravity changes on neurovascular unit and modulation of learning and memory. Front Behav Neurosci (2012) 6:64. doi:10.3389/fnbeh. 2012.00064

62. Yang JJ, Shen Z. Effects of microgravity on human cognitive function in space flight. Space Med Med Eng (Beijing) (2003) 16(6):463-7.

63. Manzey D, Lorenz B, Poljakov V. Mental performance in extreme environments: results from a performance monitoring study during a 438-day spaceflight. Ergonomics (1998) 41(4):537-59. doi:10.1080/001401398186991

64. Zhang S, Boyd J, Delaney K, Murphy TH. Rapid reversible changes in dendritic spine structure in vivo gated by the degree of ischemia. J Neurosci (2005) 25(22):5333-8. doi:10.1523/JNEUROSCI.1085-05.2005

65. Brown CE, Wong C, Murphy TH. Rapid morphologic plasticity of periinfarct dendritic spines after focal ischemic stroke. Stroke (2008) 39(4):1286-91. doi:10.1161/STROKEAHA.107.498238

Conflict of Interest Statement: The authors declare that the research was conducted in the absence of any commercial or financial relationships that could be construed as a potential conflict of interest.

Received: 31 December 2013; paper pending published: 17 February 2014; accepted: 05 May 2014; published online: 20 May 2014.

Citation: Ranjan A, Behari J and Mallick BN (2014) Cytomorphometric changes in hippocampal CA1 neurons exposed to simulated microgravity using rats as model. Front. Neurol. 5:77. doi: 10.3389/fneur.2014.00077

This article was submitted to Sleep and Chronobiology, a section of the journal Frontiers in Neurology.

Copyright (c) 2014 Ranjan, Behari and Mallick. This is an open-access article distributed under the terms of the Creative Commons Attribution License (CC BY). The use, distribution or reproduction in other forums is permitted, provided the original author(s) or licensor are credited and that the original publication in this journal is cited, in accordance with accepted academic practice. No use, distribution or reproduction is permitted which does not comply with these terms. 